\title{
Effects of the Online VOD self-learning on English ability of Taiwanese college students: The ARCS approach
}

\author{
Da-Fu Huang \\ Southern Taiwan University of Science and Technology
}

\begin{abstract}
This study investigated the effect of the Live DVD self-learning system on English learning movitvation of students of a Taiwanese technological university. Modeled on on the ARCS motivation model of Keller (1987), this study validated the ARCS model, examined the effects of Majors and English Levels on motivation, and tested the proposed structural model invovling the effect of the ARCS model on self-assessed English skills. Five hundred and twenty-seven students of three English ability groups completed a survey questionnaire. Statistical procedures including confirmatory factor analysis, factorial ANOVA, and structural equation modelling were performed to address the research questions. The participants were found to have overall positive motivation toward the Live DVD System in terms of the ARCS model. English Levels had significant influence on Attention, with students of Mid and Low-level groups having higher attention to the Live DVD system than High-level group students. For Satisfaction, aside from the main effect of English Levels, the English Levels*Majors interaction effect was also found to be statistical; for non-engineering majors, students of mid and low English abilities were found to have higher satisfaction with the Live DVD System than high proficiency students, while for Level B groups, non-engineering had higher satisfaction with the self-learning system than
\end{abstract}

engineering students. Only Confidence of the ARCS in the proposed structural model was found to have significant effect on Self-assessed Skills, students with stronger confidence tending therefore to have higher self-rated English abilities.

Keywords: Self-directed learning, ARCS, Live DVD, learning motivation

\section{Introduction}

Lack of learning motivation of students, especially those of vocational and technological universities, has long been claimed to cause ineffectiveness of English education in Taiwan. Teaching approaches geared towards initiating selfdirected learning via technologymediated support with a view to enhancing learning motivation have hence been gaining ascendancy in English learning settings across different educational levels in Taiwan. Multimedia provides variety and excitement to a computersupported teaching and learning environment, adapting instruction to the diverse learning preferences of students (Zaidel \& Luo, 2010). Advanced multimedia instruction heightens visual aspects of communication, provides dynamic learning experiences and raises learning results (Wang, 2008). Multimedia materials such as DVDs and VODs as effective self-directed learning aids enhances students' comprehension and memory, increases their motivation and promotes 
their concentration on the content in a near natural environment (Astleitner \& Wiesner, 2004; Deimann \& Keller, 2006; Guariento \& Morley, 2001). Best multimedia, however, will be rendered useless unless they are utilized by students to the utmost effect, which should be ensured through some mechanism. This consideration made Southern Taiwan University of Science \& Technology create an online VOD Self-learning System, brand named Live DVD and the first of its kind in Taiwan, where students viewed designated films as a requirement. Students were monitored of their use behaviors and tested on their learning achievement after viewing the target films and using the system's embedded language learning features, including repeated listening, vocabulary collection, dictionary, target expression searching, multiple language display mode, etc. This study aimed to understand to what extent the Live DVD System affected learning motivation, which in turn would affect self-assessed English abilities, and whether this relationship depends on majors and English levels. Specifically, this study intended to test a proposed structural equation model involving Keller (1987)'s ARCS motivation model as a framework to investigate student perceptions of the Live DVD System and its effects on self-assessed English abilities in terms of whether the system draws their attention, shows relevance to their learning goals, helps build confidence in realistic expectations and learning outcomes, and makes the learning satisfying (see Figure 1).

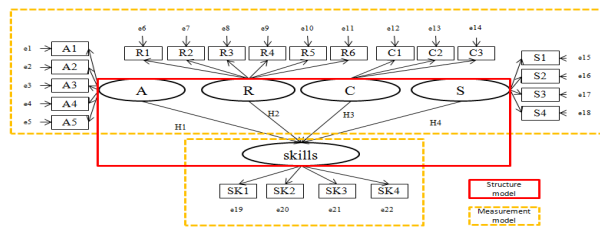

Fig. 1:The proposed structural equation model

\section{Method}

Twelve classes of first-year non-English major undergraduate students participated in the study by completing the motivation survey. The students were placed at classes of three English levels: high, mid, and low for better learning of the required English class. As a class requirement, the students did English learning by viewing the films at the Live DVD Platform, and were invited to complete the questionnaire at the semester end, with a return of 527 questionnaires. The questionnaire instrument on the 6-point Lickert scale was piloted on two classes of students and modified to insure a high reliability of the instrument for the formal data collection. After completion of data collection of 527 valid samples, confirmatory factor analysis, aside from reliability analysis, was conducted using SPSS v.18 and AMOS v.18 to check the convergent and discriminant validity of the instrument to validate the scale construct and the measurement model. Factorial ANOVA was then performed via SPSS v.18.0 to obtain the effects of Majors and English Levels on the ARCS motivation as well as the interaction effects. Structural equation modeling via AMOS was also conducted to test the hypotheses of the posited model featuring the structural model involving the effect of the ARCS motivation latent variables on Selfassessed Skills.

\section{Result}

Factor analysis employing principal component and Varimax extraction methods extracted five components including Attraction, Relevance, Confidence, Satisfcation, and Self-assessed Skills, cumutively accounting for ca. $72 \%$ of total variation. A total of 22 question items were loaded on the 5 factors: Attraction (5 items), Relevance (6 items), Confidence 
(3 items), Satisfaction (4 items), and English Skills (4 items).

The reliability of the five factors turned out to be acceptably high, with Cronbach Alpha values of $.91, .90, .74, .88$, and .90 respectively for the preceding five factors. Confirmatory factor analysis supported the acceptable convergent validity of the scale (Anderson and Gerbing, 1988; Bagozzi and Yi, 1988; Gefen, Straub and Boudreau, 2000). In ARCS motivation model, the RMR was $0.039(<0.05)$, the GFI, NFI, CFI being 0.904, 0.930, 0.947 respectively. In addition, the factor loading of each variable was significant and higher than 0.5 , the $\mathrm{CR}$ of each dimension was over 0.7, and the AVE of each dimension was larger than 0.5 . As to the Self-assessed Skills measurement model, the RMR was $0.019(<0.05)$, the GFI, NFI, CFI being 0.987, 0.988, 0.990 respectively. In addition, the variables' factor loadings were significant and higher than 0.5 , the $C R$ value over 0.7 , and the AVE value larger than 0.5 , indicating sufficient convergent validity and reliability of the model. The five components were also shown to have adequate discriminant validity complying with the rule that the correlation coefficient of two dimensions was less than the Cronbach's alpha reliability coefficients (Gaski and Nevin, 1985), and that the correlation coefficient of two dimensions was less than the square root of AVE (Fornell and Larcker,1981).

The descriptive statistics of the ARCS model indicated a grand mean of 4.34, with separate means/SDs of 4.40/.98, 4.29/.84, 4.16/.95, 4.49/.94, respectively for each of the components, indicating a fairly positive motivation toward Live DVD self learning. Two-way ANOVA was performed to examine the effects of the variables of Group (of Majors) and Level (of English Ability) on the ARCS Motivation. As shown in Table 1, main effect of English Level $(\mathrm{F}=5.88, \mathrm{p}<.01)$ was found for Attention of ARCS Model. Post-hoc comparison showed Level A to be significantly lower in attention ( $p$ $<.05)$ than Level B and Level C. Table 2 showed that main effect of English Level $(\mathrm{F}=7.96, \mathrm{p}<.01)$ and interaction effect $(\mathrm{F}=3.33, \mathrm{p}<.05)$ between Major and English Level were also found for Satisfcation of ARCS Model. In Table 3, the simple main effect of Major showed a significant difference $(\mathrm{F}=10.346, \mathrm{p}=.000)$ among non-engineering majors, where both Level B and Level C significantly surpassed Level A students in satisfaction. The simple main effect of English Level showed a significant difference $(\mathrm{F}=6.453$, $\mathrm{p}<.05)$ between non-engineering and engineering majors of Level $\mathrm{B}$, the former significantly surpassing the latter in satisfaction.

Table 1. Two-way ANOVA for Attention of ARCS Model

\begin{tabular}{|c|c|c|c|c|c|}
\hline Source & $\begin{array}{l}\text { Type III Sum of } \\
\text { Squares }\end{array}$ & df & $\begin{array}{l}\text { Mean } \\
\text { Square }\end{array}$ & $\mathbf{F}$ & Sig. \\
\hline $\begin{array}{l}\text { Corrected } \\
\text { Model }\end{array}$ & & 5 & 2.072 & 3.014 & .011 \\
\hline Intercept & 10144.505 & 1 & 10144.505 & 14751.916 & .000 \\
\hline Major & .511 & 1 & .511 & .744 & .389 \\
\hline Eng Levi & 8.084 & 2 & 4.042 & 5.878 & .003 \\
\hline Maj Levl & 1.567 & 2 & .783 & 1.139 & .321 \\
\hline Error & 358.278 & 521 & .688 & & \\
\hline Total & 10571.360 & 527 & & & \\
\hline $\begin{array}{c}\text { Corrected } \\
\text { Total }\end{array}$ & 368.640 & 526 & & & \\
\hline
\end{tabular}

$($ Eng $=$ English $;$ Maj $=$ Major $)$

Table 2. Two-way ANOVA for Satisfaction of ARCS Model

\begin{tabular}{cccccc}
\hline Source & $\begin{array}{c}\text { Type III Sum of } \\
\text { Squares }\end{array}$ & df & $\begin{array}{c}\text { Mean } \\
\text { Square }\end{array}$ & F & Sig. \\
\hline $\begin{array}{c}\text { Corrected } \\
\text { Model }\end{array}$ & 14.716 & 5 & 2.943 & 4.652 & .000 \\
Intercept & 10562.019 & 1 & 10562.019 & 16691.946 & .000 \\
Major & .313 & 1 & .313 & .495 & .482 \\
Eng Lev1 & 10.075 & 2 & 5.037 & 7.961 & .000 \\
Maj Eng Lev1 & 4.216 & 2 & 2.108 & 3.332 & .036 \\
Error & 329.669 & 521 & .633 & & \\
Total & 10968.938 & 527 & & & \\
Corrected \\
Total
\end{tabular}

$($ Eng = English $;$ Maj = Major $)$ 
Table 3. Test of simple main effect of Major and English Level on Satisfaction of ARCS Model

\begin{tabular}{|c|c|c|c|c|c|c|}
\hline & $\begin{array}{l}\text { Sum of } \\
\text { Squares }\end{array}$ & df & $\begin{array}{l}\text { Mean } \\
\text { Square }\end{array}$ & $\mathbf{F}$ & Sig & Post Hoc \\
\hline \multicolumn{7}{|l|}{ Majors } \\
\hline Engineering & 1.092 & 2 & .546 & .878 & .417 & \\
\hline Non-engineering & 13.318 & 2 & 6.659 & 10.346 & $0.000^{\circ}$ & $\begin{array}{l}\operatorname{LvB}>\operatorname{LvA} \\
\operatorname{LvC} C \operatorname{LvA} A\end{array}$ \\
\hline \multicolumn{7}{|l|}{ English Levels } \\
\hline Level A & 1.156 & 1 & 1.156 & 1.531 & .218 & \\
\hline Level B & 3.418 & 1 & 3.418 & 6.453 & $.012^{\circ}$ & $\begin{array}{l}\text { Non-engineering } \\
>\text { Engineering }\end{array}$ \\
\hline Level C & .080 & 1 & .080 & 128 & .721 & \\
\hline
\end{tabular}

Structural equation modelling was conducted to test the hypotheses of the proposed structural model. The model fit analysis includes preliminary fit criteria, fit of internal structure of model and overall model fit (Bagozzi and Yi, 1988). The analysis of absolute fit measures $(\chi 2 /$ d.f. $=\quad 2.282, \quad$ GFI $=0.929$, $\mathrm{RMR}=0.041$, RMSEA $=0.049$ ), incremental fit measures (AGFI $=0.907$, $\mathrm{CFI}=0.97$, NFI=0.947 ) and parsimonious fit measures (PNFI=0.791, PGFI= 0.709 ) suggested that the overall model fit of the proposal model after modest modification was good (Hair, Black, Babin, Anderson and Tatham, 2006).

The regression coefficients of path analyses were used for testing the hypotheses of the proposed structural model, yielding the results as represented in Table 4 and Figure 2.

Table 4. Summary of hypotheses results

\begin{tabular}{lcrcc}
\hline Hypothesized path & $\begin{array}{c}\text { Standardized Regression } \\
\text { Weights Estimate }\end{array}$ & t-value & Results \\
\hline H1 : Attention $\rightarrow$ Self-evaluated skills & 0.006 & 0.055 & NH Not Rejected \\
H2 : Relevance $\rightarrow$ Self-evaluated skills & -0.098 & -0.905 & NH Not Rejected \\
H3 : Confidence $\rightarrow$ Self-evaluated skills & $0.536^{* 8 *}$ & 6.045 & NH Rejected \\
H4 : Satisfaction $\rightarrow$ Self-evaluated skills & 0.126 & 1.26 & NH Not Rejected \\
\hline${ }^{* * *}$ p-value $<.000$. & & &
\end{tabular}

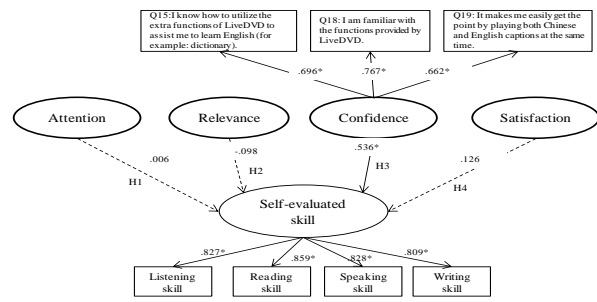

Figure 2: The structural equation model with parameter estimates

\section{Discussion}

The participants' overall fairly positive attitude toward Live DVD System suggested that the online self-learning system is a worthwhile resource for students. However, Levels B and C tended to have higher attention to the system than Level A students, implying that while boosting the learning motivation of lower end students, the system needs to be modified in the designing of learning features to appeal to the interests and motivation of higher proficiency students. Further investigation can be pursued on the difference among the three levels in the preference of the learning features on the system. From the pedagogical and placement perspectives, the precedence of Levels B and C over Level A in attention level also raised the issue of the credibility of the placement test, which might have placed medium proficiency students into Group A, and reversely high proficiency students into Group B. The validity and reliability of the placement test for the incoming undergraduates needs therefore be reviewed and improved. On the other hand, teachers of Group A classes are advised to highlight the uses of the learning system and guide them to more advanced learning results. This suggested improvement of placement and pedagogical practice seems to be particularly relevant for Non-engineering students with another result of the study showing that Levels B and C Non-engineering indicated higher satisfaction with the learning system than Level A counterparts.

The result of testing the proposed structural model indicated that in the ARCS model only Confidence had direct effect on students' self-assessed skills, reflecting the important role of selfconfidence in the learning process of college students, particularly of technological and vocational higher education, who tended to have lower learning motivation and English proficiency and hence lower 
self-confidence as well. Relative to the constructs of Attention, Relevance, and Satisfaction, Confidence, or students' perceived proficiency in using available learning features, linked to motivation most prominently in the EFL learning contexts. This research thus called attention to reinforcing of self-directed learning resources with user-friendly and practical features to build students' selfconfidence which would directly affect their perceived English learning progress, and indirectly their learning motivation.

\section{Conclusion}

This study investigated the technological university students' perceptions of the Live DVD Self-learning System by testing a hypothetical structural equation model involving the ARCS measurement model and a structural model comprising the latent variables of ARCS and Selfassessed Skills. Factors of Major and English Level were also examined as to whether they influenced students' ARCS motivations. Statistical procedures of confirmatory factor analysis, 2-way ANOVA and SEM were performed for data analysis and interpretation. The results of the study suggested an English Level effect on Attention, and a Major effect as well as a Major*English Level interaction effect on Satisfaction, engendering implications for improvement of placement test validity and reliability and teaching practice of Level A classes. More important, Confidence was validated to be the sole construct of the ARCS motivations that affected student selfassessed skills, a result that highlights the critical need of constructing self-directed learning resources in a way that would facilitate student utilization and best build self-confidence. The results of this research are significant and would be applicable to technological and vocational higher education institutions in Taiwan with similar student backgrounds for English education reform and curriculum improvement.

\section{References}

[1] Anderson, J. C., \& Gerbing, D. W. (1988). Structural equation modeling in practice: A review and recommended two-step approach. Psychological Bulletin, 103, 411-423.

[2] Astleitner, H., \& Wiesner, C. (2004). An inte grated model of multimedia learning and moti vation. Journal of Educational Multimedia and Hypermedia, 13(1), 3-22.

[3] Bagozzi, R. P. \& Yi, Y. (1988). On the evaluation of structural equation models. Journal of Academy of Marketing Science, 16, 74-94.

[4] Deimann, M., \& Keller, J. M. (2006). Volitional aspects of multimedia learning. Journal of Educational Multimedia and Hypermedia, 15(2), 137.

[5] Fornell, C., \& Larcker, D. (1981). Structural equation models with unobservable variables and measurement error. Journal of Marketing Research, 18(1), 39-50.

[6] Gaski, J. F., \& Nevin, J. R. (1985). The differential effects of exercised and unexercised power sources in a marketing channel. Journal of Marketing Research, 22(5), 130-142.

[7] Gefen, D., Straub, D. W., \& Boudreau, M. C. (2000). Structural equation modeling and regression: Guidelines for research practice. Communications of the Association for Information Systems, 7(7), 1-78.

[8] Guariento, W., \& Morley, J. (2001). Text and task authenticity in the EFL classroom. ELT Journal, 55(4), 347.

[9] Hair, J. F., Black, W. C., Babin, B. J., Anderson, R. E., \& Tatham, R. L. (2006). Multivariate data analysis $\left(6^{\text {th }}\right.$ Ed.). New Jersey: Prentice-Hall.

[10] Keller, J. M. (1987). Development and use of the ARCS model of motivational design. Journal of Instructional Development, 10(3), 2-10.

[11] Keller, J. M. (2009). Motivational design for learning and performance: The ARCS model approach. New York, NY: Springer.

[12] Wang, L. (2008). Developing and evaluating an interactive multimedia instructional tool: Learning outcomes and user experiences of optometry students. Journal of Educational Multimedia and Hypermedia, 17(1), 43.

[13] Zaidel, M., \& Luo, X. H. (2010). Effectiveness of multimedia elements in computer supported instruction: Analysis of personalization effects, students' performances and costs. Journal of College Teaching \& Learning (TLC), 7(2), 11-16. 